\title{
The spatial expression pattern of antimicrobial peptides across the healthy bovine udder
}

\author{
J. Tetens, ${ }^{* 1}$ J. J. Friedrich, ${ }^{*}$ A. Hartmann, $†$ M. Schwerin, $†$ E. Kalm, ${ }^{*}$ and G. Thaller* \\ *Institute of Animal Breeding and Husbandry, Christian-Albrechts-University Kiel, D-24098 Kiel, Germany \\ †Research Institute for the Biology of Farm Animals, Research Group for Functional Genome Analysis, D-18196 Dummerstorf, Germany
}

\begin{abstract}
Antimicrobial peptides are key molecules in local host defense. With the aim to better understand the possible involvement of these peptides in the prevention of bovine mastitis, we determined, for the first time to our knowledge, the spatial pattern of constitutive expression of 5 bovine $\beta$-defensins and bovine psoriasin (S100A 7 ) across 5 localizations of the bovine mammary gland applying a quantitative real-time PCR approach. We observed 3 different expression patterns in the healthy udder: 1) constitutive expression of the lingual and tracheal antimicrobial peptides ( $L A P$ and TAP), as well that of bovine neutrophil $\beta$-defensins 4 and $10(B N B D 4$ and $B N B D 10)$, is essentially restricted to the mammary lymph node; 2 ) bovine $\beta$-defensin 1 (DEFB1) is mainly expressed in the cisternal epithelium and the Rosette of Fürstenberg; 3) strong constitutive mRNA expression of the calcium-binding protein $S 100 A 7$, which is also known as psoriasin and which has been reported to be highly active against Escherichia coli, was detected in the streak canal. These results indicate a crucial role of $S 100 A 7$ in the early-stage prevention of coliform mastitis, and the analyzed $\beta$-defensins might be regarded as inducible weapons against already invading pathogens. Key words: antimicrobial peptide, $\beta$-defensin, psoriasin, mastitis
\end{abstract}

\section{INTRODUCTION}

Antimicrobial peptides (AMP) are substantial components of the innate immune system in a broad variety of organisms including mammals. They display direct antimicrobial activity against a wide range of pathogens and play a major role in the modulation of innate immune response (Mookherjee and Hancock, 2007). The relative importance of direct killing versus immunomodulatory function is, however, unclear (Bowdish et al., 2005).

Received September 14, 2009.

Accepted November 2, 2009.

${ }^{1}$ Corresponding author: jtetens@tierzucht.uni-kiel.de
Defensins are an important class of the vertebrate AMP divided into 3 sub-families: $\alpha-, \beta$-, and $\theta$-defensins (Ganz and Lehrer, 1998; Lehrer and Ganz, 2002). The small cyclic $\theta$-defensins are only found in nonhuman primates (Tang et al., 1999; Selsted, 2004), whereas the $\alpha$-defensins have been identified in several groups of mammals (Patil et al., 2004, 2005; Xiao et al., 2004), including the horse (Looft et al., 2006; Bruhn et al., 2007). The only sub-family found in bovines are $\beta$-defensins (Fjell et al., 2008), a large family of cationic peptides with characteristic disulfide bridging between cysteine residues (Bauer et al., 2001). Defensins can be expressed either constitutively, as seen in neutrophiland Paneth cell-derived defensins, or inducibly, as is the case for most epithelial $\beta$-defensins (Yang et al., 2004).

Several bovine $\beta$-defensins have been found to be expressed at possible sites of microbial invasion, often in an inducible manner. The tracheal antimicrobial peptide $(\boldsymbol{T A P})$ was identified in bovine tracheal epithelial cells (TEC; Diamond et al., 1991). It is expressed in the entire airway epithelium (Diamond and Bevins, 1994) and is induced in response to injury and infection (Schönwetter et al., 1995). Another AMP expressed in TEC is the lingual antimicrobial peptide $(\boldsymbol{L} \boldsymbol{A} \boldsymbol{P})$, originally discovered in squamous epithelial cells of the bovine tongue (Schönwetter et al., 1995; Russell et al., 1996). Both genes show inducible expression in cultured TEC in response to bacterial LPS and tumor necrosis factor- $\alpha$ (Diamond and Bevins, 1994; Russell et al., 1996). Unlike in TEC, the $\beta$-defensin expression in bovine alveolar macrophages is not inducible by LPS (Ryan et al., 1998).

As a part of their crucial role in local host defense, bovine $\beta$-defensins might also be involved in the prevention of udder infections (mastitis). Because of the immense economic importance of mastitis in dairy cattle, different studies have been aimed at the determination of $\beta$-defensin expression in the udder. Constitutive expression of $\beta$-defensins in the bovine mammary gland has been shown for $L A P$ and TAP, as well as for bovine neutrophil $\beta$-defensins $(\boldsymbol{B N} \boldsymbol{B D}) 3,4,5,9$, and 12, $\beta$-defensin 401, and $\beta$-defensin 1 (DEFB1), also 
known as bovine enteric $\beta$-defensin (Tarver et al., 1998; Roosen et al., 2004; Cormican et al., 2008). The latter was originally identified in the bovine small intestine and shown to be highly inducible during Cryptosporidium parvum infections (Tarver et al., 1998). Inducible expression has been shown for $B N B D 5$, which is expressed predominantly in mammary epithelial cells and is strongly upregulated in mastitis (Goldammer et al., 2004). Another study has identified the induction of several bovine $\beta$-defensins including $L A P, B N B D 4$, $B N B D 10$, and DEFB1 in response to a challenge with Escherichia coli in cultured mammary epithelial cells as well as in vivo (Günther et al., 2009). The abundance of induction seems to depend on the causative pathogen. Petzl et al. (2008) found E. coli to be a potent inducer of the innate immune defense including defensin expression, whereas Staphylococcus aureus was not able to trigger this early response.

Additionally, a broad spectrum of antibacterial and antifungal activities has been demonstrated for several bovine $\beta$-defensins: $L A P, T A P$, and BNBD12 exhibit high activities against gram-negative $E$. coli and grampositive Staph. aureus, which are characteristic mastitis-causing pathogens (Diamond et al., 1991; Schönwetter et al., 1995; Mandal et al., 2002). Consequently, $\beta$-defensins have also been studied at the genomic level with regard to mastitis and SCC in dairy cattle. Several studies have identified associations between $\beta$-defensin polymorphisms and SCC in Polish Holstein-Friesian and Jersey cows (Ryniewicz et al., 2002, 2003; WojdakMaksymiec et al., 2006; Bagnicka et al., 2007).

Another important antimicrobial agent present in bovines is the calcium-binding S100A7 protein (Hitomi et al., 1996), also known as psoriasin (Madsen et al., 1991; Broome et al., 2003; Gläser et al., 2005). It is highly active especially against several strains of $E$. coli in humans (Gläser et al., 2005) and cattle (Regenhard et al., 2009), and its expression is inducible by proinflammatory cytokines and bacteria (Gläser et al., 2005).

Constitutive and inducible expression in the bovine udder and antibacterial activity against pathogens indicate a crucial role of $\beta$-defensins and psoriasin in the local host defense against mastitis. Antimicrobial peptides able to establish an effective barrier should show a remarkable level of constitutive expression at the sites of bacterial invasion, whereas the expression of those acting as weapons against already invading pathogens should be highly inducible. The aim of this study was therefore to determine the constitutive expression level of $\beta$-defensins and psoriasin in different localizations of the healthy bovine udder to gather further evidence for the potential role of AMP in resistance to mastitis.

\section{MATERIALS AND METHODS}

\section{Collection of Tissue Samples}

Samples from different localizations of the healthy bovine udder were taken from 9 first-lactation German Holstein dairy cows. These animals were kept under the national guidelines for animal experiments and according to standard dairy farm practice without any intervention in the living animal. The study was approved by an institutional committee. To control for extraneous sources of variation, all animals were kept under the same environmental conditions. After parturition, udder health was controlled weekly by measuring SCC in milk samples and with clinical investigations. Milk samples from each quarter were tested for bacterial infection upon slaughtering at d 42 postpartum. All cows were milked 2 times a day with a $12-\mathrm{h}$ interval. All animals included in the study were clinically healthy, the SCC was routinely $<100,000$ cells $/ \mathrm{mL}$, and cows did not show any indication of bacterial infection on the day of slaughter. Immediately after the animals were killed, tissue samples of the gland cisternal epithelium, the parenchyma (deep in the secretory part), the Rosette of Fuerstenberg, the streak canal, and the inguinal lymph node were removed from the left rear quarter, frozen immediately in liquid nitrogen, and stored at $-80^{\circ} \mathrm{C}$ until isolation of RNA. Frozen tissues were ground with a mortar in liquid nitrogen. Homogenization of ground tissue samples was done with $1 \mathrm{~mL}$ of TRI Reagent (Sigma, Taufkirchen, Germany) using syringes and needles. For all tissues except inguinal lymph node, a proteinase $\mathrm{K}$ digestion was carried out. Then, RNA was isolated with the RNeasy Mini Kit (Qiagen, Hilden, Germany) according to the manufacturer's protocol including an additional DNase treatment. The RNA was then quantified and its quality checked by gel electrophoresis on a 1\% agarose gel. All RNA samples were checked for DNA contamination by performing an intron-spanning PCR using the reference gene primers.

\section{Quantitative Real-Time PCR}

To obtain cDNA, $250 \mathrm{ng}$ of each total RNA template was subjected to reverse transcription using 200 U of Superscript III reverse transcriptase (Invitrogen, Karlsruhe, Germany). The reaction was carried out as described in the manufacturer's instructions in a final volume of $20 \mu \mathrm{L}$ containing $25 \mu \mathrm{mol} / \mathrm{L}(\mu M)$ of dNTPs and $0.5 \mu \mathrm{M}$ of oligo-dT primers.

The quantitative real-time (qRT)-PCR primers (Table 1) were designed using the Primer3 software (http:// frodo.wi.mit.edu/primer3/) and synthesized by biomers. 
Table 1. Gene-specific primers $(\mathrm{F}=$ forward; $\mathrm{R}=$ reverse) used in quantitative real-time PCR

\begin{tabular}{|c|c|c|}
\hline Gene $^{1}$ & Primer $\left(5^{\prime} \text { to } 3^{\prime}\right)^{1}$ & Amplicon size, bp \\
\hline \multirow[t]{2}{*}{$G A P D H$} & F: GGAGAAACCTGCCAAGTATGATG & 193 \\
\hline & R: CCAGGAAATGAGCTTGACAAAGT & \\
\hline \multirow{2}{*}{$B N B D 4$} & F: CGTTCTTGTGCCGTGTAG & 149 \\
\hline & R: AAATTTTAGACGGTGTGTTG & \\
\hline \multirow[t]{2}{*}{$B N B D 10$} & F: AGTTATCTAAGCTGCTGGG & 173 \\
\hline & R: CGCTCTGTCAAAGGGTC & \\
\hline \multirow[t]{2}{*}{$D E F B 1$} & F: RD-ATCCTCTAAGCTGCCGTCT & 102 \\
\hline & R: RD-AGCATTTTACTGAGGGCGT & \\
\hline \multirow[t]{2}{*}{$L A P$} & F: RD-GATTGGCACCTGTCTCGGAG & 132 \\
\hline & R: RD-TATTCTGGTTTAAATTTTAAACTCTCTGTCC & \\
\hline \multirow{2}{*}{ TAP } & F: RD-GAGTAGGAAATCCTGTAAGCTGT & 135 \\
\hline & R: RD-TGGCCTTCTTTTACTTCTTTCTA & \\
\hline \multirow[t]{2}{*}{ S100A7 } & F: RD-AGAGCAGGCCATTACAGACT & 218 \\
\hline & R: RD-CAAGGACAGGAACTCAGA & \\
\hline
\end{tabular}

${ }^{1} B N B D 4=$ bovine neutrophil $\beta$-defensin $4 ; B N B D 10=$ bovine neutrophil $\beta$-defensin $10 ; D E F B 1=$ bovine $\beta$-defensin $1 ; L A P=$ lingual antimicrobial peptide; $T A P=$ tracheal antimicrobial peptide; $S 100 A 7=$ bovine psoriasin.

${ }^{2}$ Primers appended with RD have a robust dosage tail (ggccaagtgt) attached to the $5^{\prime}$ end.

net (Ulm, Germany). A robust dosage tail was added to the $5^{\prime}$ end of some primers (Liu et al., 2003), because they were also used in subsequent experiments with respect to copy number variation of bovine $\beta$-defensins. To ensure gene specificity of primers in view of the high degree of sequence similarity between the analyzed $\beta$-defensin genes (all orthologs of the human DEFB4 gene), sequences available in public databases (mRNA, expressed sequence tags, genomic) were aligned using the Multalin software (Corpet, 1988). Thereby, we were able to determine those sequence differences defining the most unambiguous gene-specific primer binding sites for at least one of the primers (Figure 1). In addition to the target genes, PCR primers for bovine $G A P D H$ were designed that served as reference gene.

Quantification was done applying the standard curve method based on a dilution series of target gene plasmids. For construction of these plasmids, PCR products were purified from a preparative agarose gel using a PCR purification kit (Qiagen), cloned into a pDrive vector, and transformed into competent $E$. coli cells using the Qiagen PCR cloning plus kit according to the manufacturer's instructions. Plasmid DNA was prepared using the Fast Plasmid Mini Kit (Eppendorf, Hamburg, Germany), and each preparation was first subjected to a test PCR and subsequently sequenced to ensure the presence of the correct insert.

The qRT-PCR was carried out on an iQ5 Multicolor Real-Time PCR Detection System (Bio-Rad, Munich, Germany). The reactions were set up in a final volume of $20 \mu \mathrm{L}$ containing $0.4 \mu \mathrm{M}$ of each primer using the Platinum SYBR Green qPCR Super Mix UDG Kit (Invitrogen). As template, $2 \mu \mathrm{L}$ of cDNA was used, corresponding to $1.56 \mathrm{ng}$ of total RNA. The following protocol was used: after an initial denaturation at $95^{\circ} \mathrm{C}$, 40 cycles were performed consisting of denaturation $\left(95^{\circ} \mathrm{C}\right.$ for $\left.15 \mathrm{~s}\right)$, annealing $\left(58^{\circ} \mathrm{C}\right.$ for $\left.30 \mathrm{~s}\right)$, elongation $\left(72^{\circ} \mathrm{C}\right.$ for $\left.30 \mathrm{~s}\right)$, and a high-temperature fluorescence acquisition step $\left(79^{\circ} \mathrm{C}\right.$ for $\left.30 \mathrm{~s}\right)$ (Pfaffl, 2001). This protocol was followed by a melting curve analysis. The threshold cycle $\left(\mathbf{C}_{t}\right)$ of a sample was set at the cycle number at which the fluorescence signal intersected the threshold automatically determined by the iQ5 Optical System Software (Bio-Rad), so that the fluorescence signal exceeded the background noise. All reactions were done in triplicate and, on each reaction plate, a 1:10 dilution series of the target gene plasmid was included, corresponding to a theoretical range from 4.42 $\times 10^{7}$ to 4.42 mRNA copies.

\section{Analysis of Real-Time PCR Data}

The statistical analysis of the real-time PCR data was carried out using the $\mathrm{R}$ statistical software (R Development Core Team, 2008). All triplicate measurements were checked for uniformity using the outlier test according to Nalimov (1963). If 1 of the 3 measurements was found to be an outlier with an error probability below 0.05 , this value was rejected using the means of the remaining values for subsequent analyses. The plasmid dilution series was used to determine the range of linear dependency between the dyadic logarithm of the template concentration and the $\mathrm{C}_{t}$ value for each target gene. If deviation from linearity with no or close to no increase of the $\mathrm{C}_{\mathrm{t}}$ value for the highest dilution steps was observed, a product-specific virtual detection limit was defined to avoid false-positive results or a massive overestimation of exceedingly low mRNA expression levels. The target gene measurements were normalized against GAPDH for all samples to make the results comparable between animals as well as between the different localizations. From these normalized values, the 


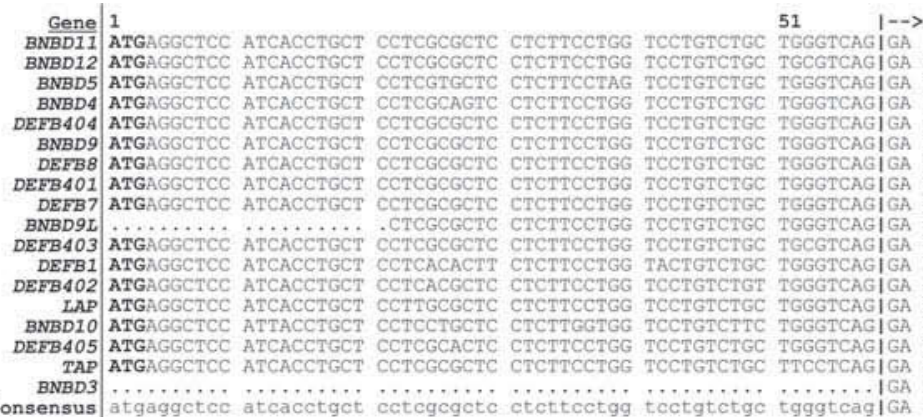

51

$1->$ Exon 2

... AtaAgtgG tectctaagc tgccGtagGa 10

101

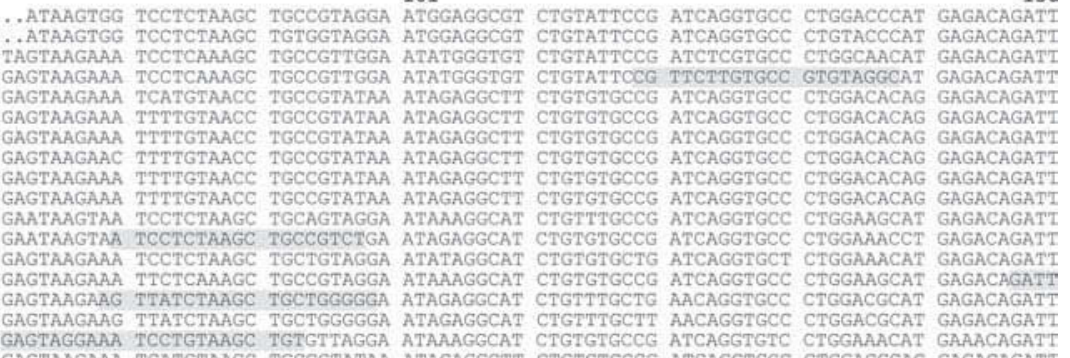

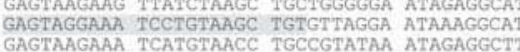

BNBD 151 201
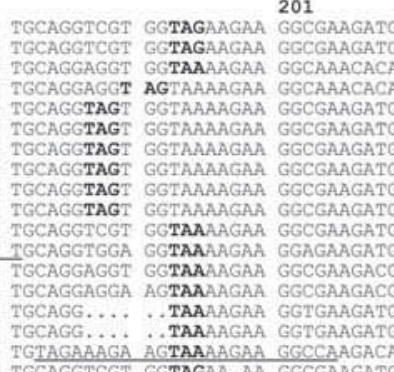

$\mathrm{CYs}_{1}$
251

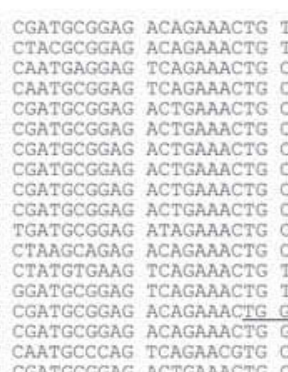

$\mathrm{Cys}_{2}$

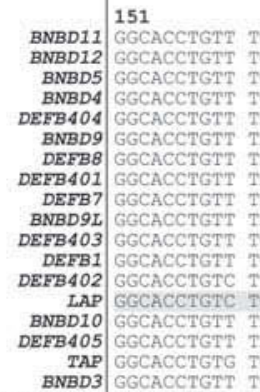

$\mathrm{CYs}_{4}$ $\mathrm{CYs}_{5} \mathrm{CYs}_{6}$

Figure 1. Alignment of available bovine mRNA sequences orthologous to human $\beta$-defensin 4 (DEFB4). The alignment contains one representative sequence per gene and runs from the start codon to position 280 of the open reading frame. Start and stop codons are printed in bold letters, and the boundary between exon 1 and 2 is indicated by vertical dashes. The characteristic cysteine residues are marked within the consensus sequence. Within the sequences of the analyzed $\beta$-defensins, gene-specific PCR-primers are highlighted (forward primer $=$ gray background, reverse primer $=$ underlined $).$ 
number of mRNA copies was calculated based on the standard curve obtained from linear regression of the plasmid dilution series and scaled to the mRNA copy number per nanogram of total RNA initially subjected to reverse transcription.

\section{RESULTS}

\section{Performance of $q R T-P C R$}

For all target genes, the PCR efficiencies were calculated as the slope of the standard curve and found to be close to 1 . The efficiencies of repeated measures of the same target gene were within a range of \pm 1 standard deviation. For $L A P$ and $S 100 A 7$, a detection limit had to be set at $44.2 \mathrm{mRNA}$ copies/ng of total RNA because of a deviance from linearity for the highest dilution step. The melting curve analysis revealed no signs of additional unspecific PCR products, indicating that the primer pairs were specific. The stability of the housekeeping gene appeared to be good with a mean $\mathrm{C}_{\mathrm{t}}$ standard deviation between repeated measures below 0.5 cycles.

\section{Constitutive Expression of AMP in the Healthy Udder}

The mRNA expression levels for $L A P, T A P, D E F B 1$, $B N B D 4, B N B D 10$, and S100A7 are shown in Figure 2 . The 2 epithelial $\beta$-defensins $L A P$ and $T A P$ as well as the neutrophil $\beta$-defensins BNBD4 and BNBD10 exhibited similar expression patterns with the highest amount of mRNA detected in the lymph node, followed by the cisternal epithelium, and no or close to no expression in the parenchyma. The abundance of $L A P$ and $B N B D 10$ mRNA expression in the lymph node was at least an order of magnitude higher than that for TAP and BNBD4. The expression pattern of DEFB1 was found to differ from that of the other $\beta$-defensins, because the highest abundance was found in the cisternal epithelium followed by the Rosette of Fürstenberg and only marginal mRNA expression in the lymph node and streak canal. The overall abundance of $D E F B 1$ was comparable to the levels of $T A P$ and $B N B D 4$. The level of $S 100 A 7 \mathrm{mRNA}$ expression was found to be very high in the streak canal and the Rosette of Fürstenberg with a level of $2.78 \times 10^{6} \mathrm{mRNA}$ copies/ng of total RNA in the streak canal. In the other tissues no S100A7mRNA expression could be detected. As indicated in Figure 2, the standard errors were relatively high for all analyzed genes.

The tissue distribution of the target gene mRNA expression is shown in Figure 3. The highest total abundance was seen in the streak canal and, to a lower extent, in the Rosette of Fürstenberg and was almost solely because of the very high level of $S 100 A 7$ message detected. The lowest level of mRNA expression was found in the udder parenchyma, whereas the levels in the cisternal epithelium and the lymph node were higher with a total abundance of $2.69 \times 10^{3}$ and $2.13 \times 10^{4}$ mRNA copies/ng of total RNA, respectively. This can be assigned mainly to $L A P$ and $B N B D 10$ transcripts.

\section{DISCUSSION}

Transcript analyses of bovine $\beta$-defensins are hampered by the problem of high sequence similarity. The $\beta$-defensins analyzed within this study are all orthologous to human DEFB4, and the similarity between them ranged from $81 \%$ ( $T A P$ vs. $B N B D 10$ ) to $86 \%$ ( $D E F B 1$ vs. $L A P / T A P$ and $L A P$ vs. TAP). The highest degree of similarity to one of the other bovine $\beta$-defensins listed in Figure 1 was found for DEFB1, which showed $97 \%$ identity with DEFB405. Especially in microarray studies, it is therefore not always possible to distinguish between different $\beta$-defensins based on the available probe sets. In comparative studies, this could lead to an overestimation of fold changes due to an admixture of several inducible $\beta$-defensins.

The results of transcript quantification in different localizations of the healthy bovine udder indicated the presence of 3 different patterns of constitutive expression among the analyzed AMP. The constitutive expression of $L A P, T A P, B N B D 4$, and $B N B D 10$ was essentially restricted to the lymph node with different total abundances. The expression of DEFB1 was located more distally in the cisternal epithelium and the Rosette of Fürstenberg, whereas S100A7 expression was exclusively detected in the streak canal and the Rosette of Fürstenberg. The abundance of S100A7 transcripts resulted in the highest overall AMP transcription level in these locations. Generally, abundance decreases with an increasing distance to the site of possible bacterial invasion (streak canal $>$ Rosette of Fürstenberg $>$ gland cisternal epithelium $>$ parenchyma). An exception of this coherence is the lymph node, probably because of the $\beta$-defensin expression of neutrophils residing there. The biggest part of the total transcript level in the parenchyma can be ascribed to $L A P$, which is in concordance with other studies locating $L A P$ expression to alveolar epithelial cells (Swanson et al., 2004; Isobe et al., 2009). Summarizing the patterns of constitutive expression, we hypothesize that $S 100 A 7$, which is highly active against $E$. coli (Gläser et al., 2005; Regenhard et al., 2009) and inducible in skin (Gläser et al., 2005; Regenhard et al., 2009), forms an effective barrier against bacterial invasion and could be crucial in preventing coliform mastitis. Additionally, other calcium-binding S100A 

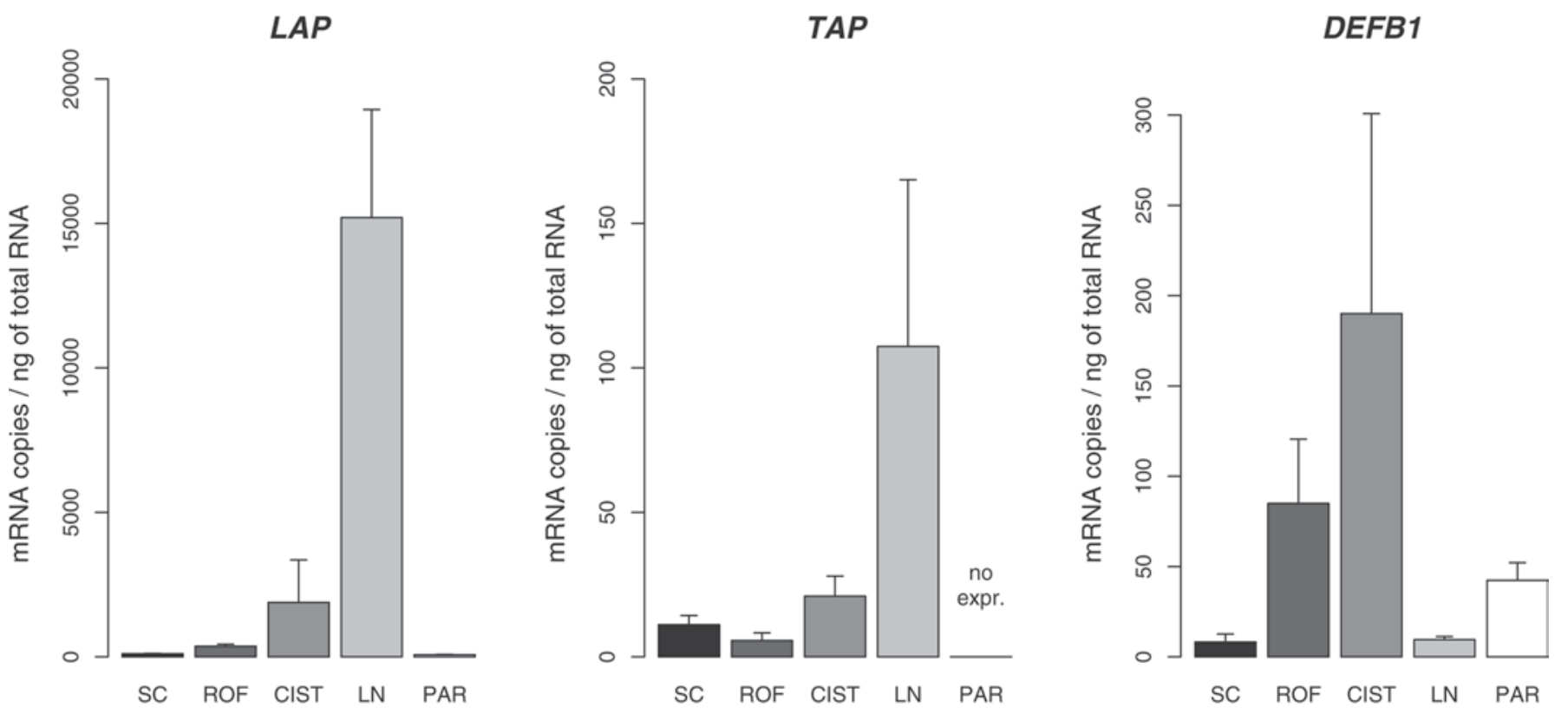

\section{BNBD4}

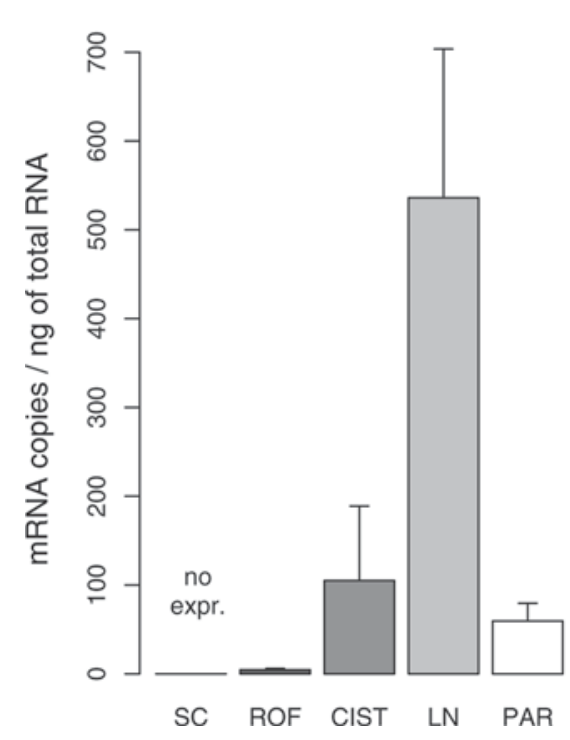

BNBD10

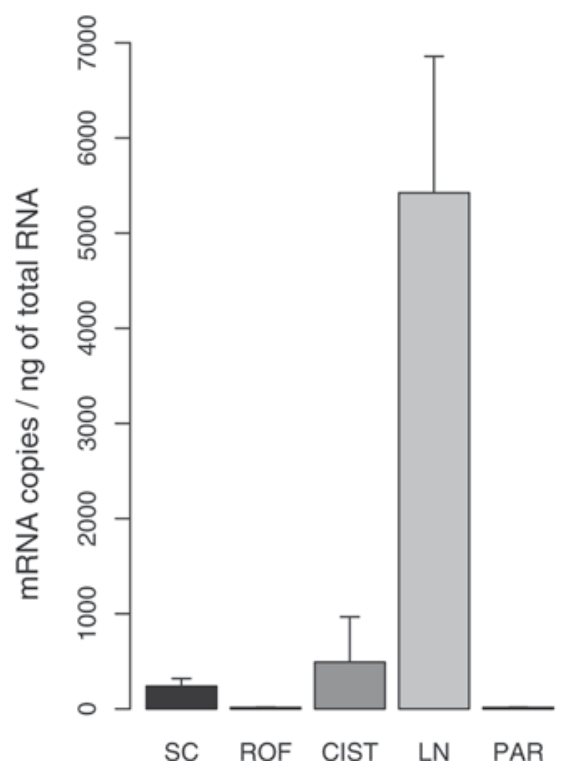

S100A7

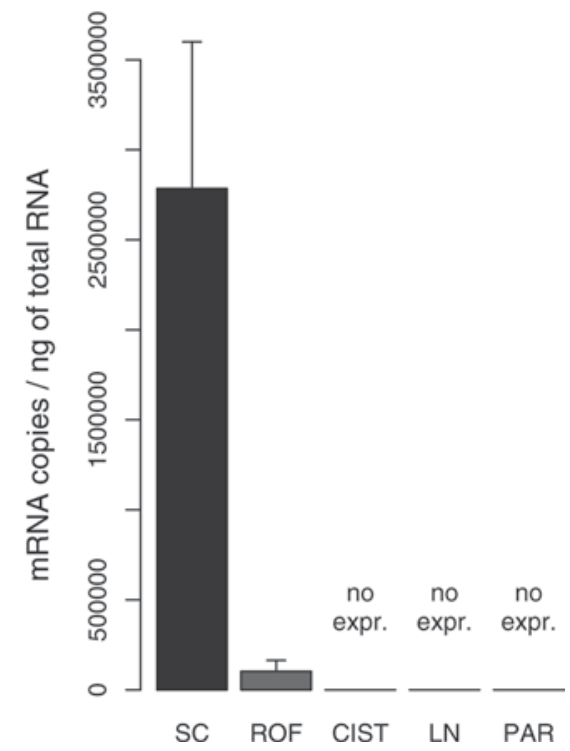

Figure 2. mRNA expression level of 5 bovine $\beta$-defensins and bovine psoriasin $(S 100 A 7)$ in 5 different localizations of the udder (SC $=$ streak canal, ROF $=$ Rosette of Fürstenberg, CIST $=$ gland cisternal epithelium, LN = inguinal lymph node, PAR $=$ udder parenchyma). The mean numbers of mRNA copies per nanograms of total RNA normalized against GAPDH are shown. The error bars depict the standard error; no expr. $=$ no expression, meaning that no transcripts were detectable above the detection limit. $B N B D 4=$ bovine neutrophil $\beta$-defensin $4 ; B N B D 10=$ bovine neutrophil $\beta$-defensin $10 ; D E F B 1=$ bovine $\beta$-defensin $1 ; L A P=$ lingual antimicrobial peptide; TAP = tracheal antimicrobial peptide.

proteins, namely S100A9 and S100A12, have been found to be induced in the udder by E. coli infections (Günther et al., 2009). Regarding the housing conditions of dairy cows, the exceedingly high transcript level could therefore also be the result of a permanent and recurrent induction by coliforms at the orifice of the streak canal without any signs of infection. To further elucidate this hypothesis, future studies should investigate S100A7 expression at different locations of the skin including sites far away from the galactogenic pathway of infection, probably in animals housed under different conditions. 


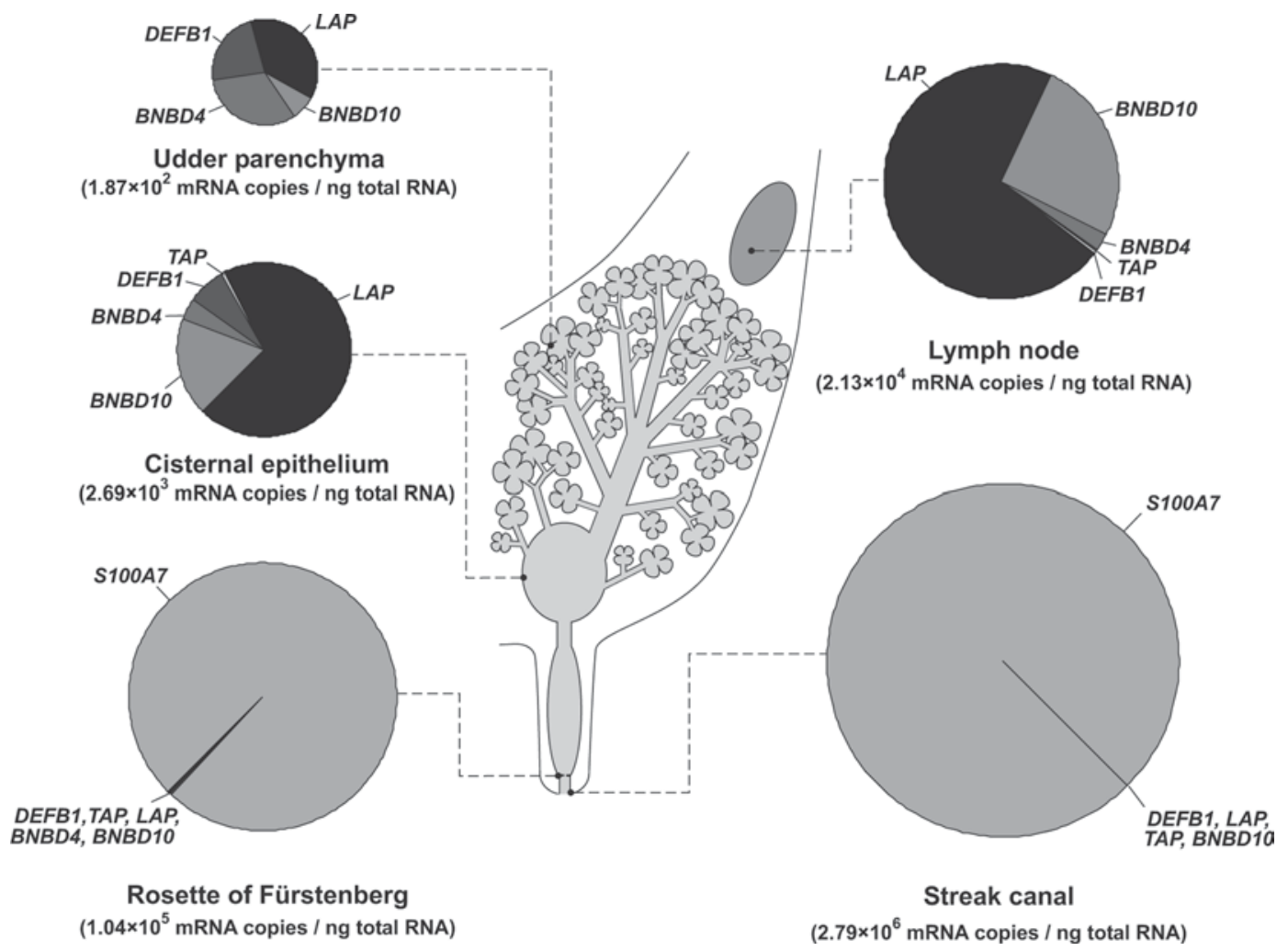

Figure 3. Tissue distribution of the mRNA expression levels. The values represent the mean numbers of mRNA copies per nanograms of total RNA normalized against GAPDH. The diameter of the pie charts corresponds to the overall abundance at that localization, which is additionally given below each chart. $B N B D 4=$ bovine neutrophil $\beta$-defensin $4 ; B N B D 10=$ bovine neutrophil $\beta$-defensin $10 ; D E F B 1=$ bovine $\beta$-defensin 1 ; $L A P=$ lingual antimicrobial peptide; $T A P=$ tracheal antimicrobial peptide; $S 100 A 7=$ bovine psoriasin.

A conclusion regarding the role of the analyzed $\beta$-defensins cannot be clearly drawn from our data. Having been shown to be inducible in the mammary gland (Günther et al., 2009), $L A P, B N B D 4, B N B D 10$, and $D E F B 1$ might act as inducible weapons against invading pathogens. Considering the fact that LAP makes up approximately $70 \%$ of the total transcript level in cisternal epithelium in our study, an intermediate role could be suggested for this AMP.

The high individual variability of constitutive AMP expression (Figure 2) is a major finding of the current study that might indicate the presence of a genetically determined different expression level. Although management factors play an important role in mastitis control, resistance to udder infections has a substantial genetic component, giving the possibility of genetic improvement.

In many countries, selection for udder health is based on the indicator trait SCS. In the literature, selection based on SCS is controversially discussed. Weller et al. (1992) reported the genetic correlation between SCS and subclinical mastitis to be near unity, whereas in the same study the correlation between SCS and clinical mastitis was found to be only 0.3. This finding indicates that SCS can be used to select for a lower incidence of subclinical, but not clinical, mastitis. On the other hand, Carlen et al. (2004) reported mean genetic correlations between mastitis and SCS in Swedish Holstein cows of 0.7 , indicating the usefulness of SCS in breeding for a low incidence of clinical mastitis. However, the genetic improvement of udder health based solely on SCS bears the risk of impairing mechanisms related to the recruitment of neutrophils. Regarding the essential role of these cells in the immune response of the mammary gland (Burton and Erskine, 2003), this could lead to a decreased ability to fight arising udder infections. Effective breeding for udder health would therefore probably benefit from the discovery and utilization of mechanisms directly affecting the innate immune response such as the abundance of AMP expression in the mammary gland. Different QTL mapping studies have identified the 2 bovine $\beta$-defensin clusters on chromosomes 13 and 27 as candidate regions affecting SCS (Kühn et al., 2003; Rupp and Boichard, 2003; Ashwell et al., 2004), with the latter containing the $\beta$-defensins analyzed in the current study. The region of bovine chromosome 3 containing $S 100 A 7$ has also been identified as a QTL region for SCS (Klungland et al., 2001). 
Considering the genomic structure of the human $\beta$-defensin cluster on human chromosome 8 (Groth et al., 2008, Hollox et al., 2008; Abu Bakar et al., 2009), it seems likely that copy number variation $(\mathbf{C N V})$ might represent a major source of genomic variation related to individual differences in the innate immune response based on AMP. The available genomic tools in cattle, essentially the whole-genome BovineSNP50 SNP Chip (Illumina, San Diego, CA; Matukumalli et al., 2009), are not capable of covering this kind of variation. It is possible to detect CNV using SNP genotyping arrays, and the bovine 50k array has already been applied to the detection of large-scale CNV (Matukumalli et al., 2009), but reliable copy number detection for single genes requires a much higher SNP density (Carter, 2007). Additionally, the design of robust genotyping SNP assays is particularly difficult within regions containing segmental duplications and complex CNV (Carter, 2007). Because of this, the marker coverage of the BovineSNP50 Chip contains a gap spanning the entire bovine $\beta$-defensin cluster on chromosome 27 . Further elucidation of the effect of $\mathrm{CNV}$ on the individual ability of local host defense, therefore, will benefit from the availability of advanced genomic tools.

\section{CONCLUSIONS}

For the first time to our knowledge, the data presented in this study provide a spatial expression pattern for different AMP across the healthy bovine udder. We demonstrated that the constitutive expression of $L A P$, $T A P, B N B D 4$, and $B N B D 10$ is essentially restricted to the lymph node, whereas expression of $D E F B 1$ occurs in more distal regions of the mammary gland. Strong constitutive mRNA expression of S100A\%, which is highly active against $E$. coli, was detected in the streak canal, suggesting this AMP to be crucial in the early-stage prevention of coliform mastitis. To identify genomic variation responsible for individual differences in AMP expression might, beyond current approaches, be useful in improving udder health.

\section{ACKNOWLEDGMENTS}

The authors acknowledge the expert technical assistance of H. Kluding and G. Ottzen-Schirakow (Institute of Animal Breeding and Husbandry, Christian-Albrechts University, Kiel, Germany). This study was partly funded by the German Federal Ministry of Education and Research (Fkz: 0313390D).

\section{REFERENCES}

Abu Bakar, S., E. J. Hollox, and J. A. Armour. 2009. Allelic recombination between distinct genomic locations generates copy number diversity in human beta-defensins. Proc. Natl. Acad. Sci. USA $106: 853-858$.
Ashwell, M. S., D. W. Heyen, T. S. Sonstegard, C. P. Van Tassell, Y. Da, P. M. VanRaden, M. Ron, J. I. Weller, and H. A. Lewin. 2004. Detection of quantitative trait loci affecting milk production, health, and reproductive traits in Holstein cattle. J. Dairy Sci. $87: 468-475$.

Bagnicka, E., N. Strzalkowska, K. Flisikowski, T. Szreder, A. Jozwik, B. Prusak, J. Krzyzewski, and L. Zwierzchowski. 2007. The polymorphism in the beta4-defensin gene and its association with production and somatic cell count in Holstein-Friesian cows. J. Anim. Breed. Genet. 124:150-156.

Bauer, F., K. Schweimer, E. Kluver, J. R. Conejo-Garcia, W. G. Forssmann, P. Rosch, K. Adermann, and H. Sticht. 2001. Structure determination of human and murine beta-defensins reveals structural conservation in the absence of significant sequence similarity. Protein Sci. 10:2470-2479.

Bowdish, D. M., D. J. Davidson, and R. E. Hancock. 2005. A reevaluation of the role of host defence peptides in mammalian immunity. Curr. Protein Pept. Sci. 6:35-51.

Broome, A. M., D. Ryan, and R. L. Eckert. 2003. S100 protein subcellular localization during epidermal differentiation and psoriasis. J. Histochem. Cytochem. 51:675-685.

Bruhn, O., P. Regenhard, M. Michalek, S. Paul, C. Gelhaus, S Jung, G. Thaller, R. Podschun, M. Leippe, J. Grötzinger, and E. Kalm. 2007. A novel horse alpha-defensin: Gene transcription, recombinant expression and characterization of the structure and function. Biochem. J. 407:267-276.

Burton, J. L., and R. J. Erskine. 2003. Immunity and mastitis. Some new ideas for an old disease. Vet. Clin. North Am. Food Anim. Pract. 19:1-45, v.

Carlen, E., E. Strandberg, and A. Roth. 2004. Genetic parameters for clinical mastitis, somatic cell score, and production in the first three lactations of Swedish Holstein cows. J. Dairy Sci. 87:30623070 .

Carter, N. P. 2007. Methods and strategies for analyzing copy number variation using DNA microarrays. Nat. Genet. 39:S16-S21.

Cormican, P., K. G. Meade, S. Cahalane, F. Narciandi, A. Chapwanya, A. T. Lloyd, and C. O'Farrelly. 2008. Evolution, expression and effectiveness in a cluster of novel bovine beta-defensins. Immunogenetics 60:147-156.

Corpet, F. 1988. Multiple sequence alignment with hierarchical clustering. Nucleic Acids Res. 16:10881-10890.

Diamond, G., and C. L. Bevins. 1994. Endotoxin upregulates expression of an antimicrobial peptide gene in mammalian airway epithelial cells. Chest 105(Suppl):51S-52S.

Diamond, G., M. Zasloff, H. Eck, M. Brasseur, W. L. Maloy, and C. L. Bevins. 1991. Tracheal antimicrobial peptide, a cysteine-rich peptide from mammalian tracheal mucosa: Peptide isolation and cloning of a cDNA. Proc. Natl. Acad. Sci. USA 88:3952-3956.

Fjell, C. D., H. Jenssen, P. Fries, P. Aich, P. Griebel, K. Hilpert, R. E. Hancock, and A. Cherkasov. 2008. Identification of novel host defense peptides and the absence of alpha-defensins in the bovine genome. Proteins 73:420-430.

Ganz, T., and R. I. Lehrer. 1998. Antimicrobial peptides of vertebrates. Curr. Opin. Immunol. 10:41-44.

Gläser, R., J. Harder, H. Lange, J. Bartels, E. Christophers, and J. M. Schröder. 2005. Antimicrobial psoriasin (S100A7) protects human skin from Escherichia coli infection. Nat. Immunol. 6:57-64.

Goldammer, T., H. Zerbe, A. Molenaar, H. J. Schuberth, R. M. Brunner, S. R. Kata, and H. M. Seyfert. 2004. Mastitis increases mammary mRNA abundance of beta-defensin 5, toll-like-receptor 2 (TLR2), and TLR4 but not TLR9 in cattle. Clin. Diagn. Lab. Immunol. 11:174-185.

Groth, M., K. Szafranski, S. Taudien, K. Huse, O. Mueller, P. Rosenstiel, A. O. H. Nygren, S. Schreiber, G. Birkenmeier, and M. Platzer. 2008. High-resolution mapping of the 8p23.1 beta-defensin cluster reveals strictly concordant copy number variation of all genes. Hum. Mutat. 29:1247-1254.

Günther, J., D. Koczan, W. Yang, G. Nürnberg, D. Repsilber, H. J. Schuberth, Z. Park, N. Maqbool, A. Molenaar, and H. M. Seyfert. 2009. Assessment of the immune capacity of mammary epithelial 
cells: Comparison with mammary tissue after challenge with Escherichia coli. Vet. Res. 40:31.

Hitomi, J., K. Maruyama, Y. Kikuchi, K. Nagasaki, and K. Yamaguchi. 1996. Characterization of a new calcium-binding protein abundant in amniotic fluid, CAAF2, which is produced by fetal epidermal keratinocytes during embryogenesis. Biochem. Biophys. Res. Commun. 228:757-763.

Hollox, E. J., J. C. Barber, A. J. Brookes, and J. A. Armour. 2008. Defensins and the dynamic genome: What we can learn from structural variation at human chromosome band 8p23.1. Genome Res. 18:1686-1697.

Isobe, N., K. Hosoda, and Y. Yoshimura. 2009. Immunolocalization of lingual antimicrobial peptide (LAP) in the bovine mammary gland. Anim. Sci. J. 80:446-450.

Klungland, H., A. Sabry, B. Heringstad, H. G. Olsen, L. Gomez-Raya, D. I. Vage, I. Olsaker, J. Odegard, G. Klemetsdal, N. Schulman, J. Vilkki, J. Ruane, M. Aasland, K. Ronningen, and S. Lien. 2001. Quantitative trait loci affecting clinical mastitis and somatic cell count in dairy cattle. Mamm. Genome 12:837-842.

Kühn, Ch., J. Bennewitz, N. Reinsch, N. Xu, H. Thomsen, C. Looft, G. A. Brockmann, M. Schwerin, C. Weimann, S. Hiendleder, G. Erhardt, I. Medjugorac, M. Förster, B. Brenig, F. Reinhardt, R. Reents, I. Russ, G. Averdunk, J. Blumel, and E. Kalm. 2003. Quantitative trait loci mapping of functional traits in the German Holstein cattle population. J. Dairy Sci. 86:360-368.

Lehrer, R. I., and T. Ganz. 2002. Defensins of vertebrate animals. Curr. Opin. Immunol. 14:96-102.

Liu, Q., X. Li, J. S. Chen, and S. S. Sommer. 2003. Robust dosagePCR for detection of heterozygous chromosomal deletions. Biotechniques 34:558-562, 565-556, 568.

Looft, C., S. Paul, U. Philipp, P. Regenhard, H. Kuiper, O. Distl, B. P. Chowdhary, and T. Leeb. 2006. Sequence analysis of a $212 \mathrm{~kb}$ defensin gene cluster on ECA 27q17. Gene 376:192-198.

Madsen, P., H. H. Rasmussen, H. Leffers, B. Honoré, K. Dejgaard, E. Olsen, J. Kiil, E. Walbum, A. H. Andersen, B. Basse, J. B. Lauridsen, G. P. Ratz, A. Celis, J. Vandekerckhove, and J. E. Celis. 1991. Molecular cloning, occurrence, and expression of a novel partially secreted protein "psoriasin" that is highly upregulated in psoriatic skin. J. Invest. Dermatol. 97:701-712.

Mandal, M., M. V. Jagannadham, and R. Nagaraj. 2002. Antibacterial activities and conformations of bovine beta-defensin BNBD-12 and analogs: Structural and disulfide bridge requirements for activity. Peptides 23:413-418.

Matukumalli, L. K., C. T. Lawley, R. D. Schnabel, J. F. Taylor, M. F. Allan, M. P. Heaton, J. O'Connell, S. S. Moore, T. P. Smith, T. S. Sonstegard, and C. P. Van Tassell. 2009. Development and characterization of a high density SNP genotyping assay for cattle. PLoS ONE 4:e5350.

Mookherjee, N., and R. E. Hancock. 2007. Cationic host defense peptides: Innate immune regulatory peptides as a novel approach for treating infections. Cell. Mol. Life Sci. 64:922-933.

Nalimov, V. V. 1963. The Application of Mathematical Statistics to Chemical Analysis. Pergamon Press, Oxford, UK.

Patil, A., A. L. Hughes, and G. Zhang. 2004. Rapid evolution and diversification of mammalian alpha-defensins as revealed by comparative analysis of rodent and primate genes. Physiol. Genomics 20:1-11.

Patil, A. A., Y. Cai, Y. Sang, F. Blecha, and G. Zhang. 2005. Crossspecies analysis of the mammalian beta-defensin gene family: Presence of syntenic gene clusters and preferential expression in the male reproductive tract. Physiol. Genomics 23:5-17.

Petzl, W., H. Zerbe, J. Günther, W. Yang, H. M. Seyfert, G. Nürnberg, and H. J. Schuberth. 2008. Escherichia coli, but not Staphylococcus aureus triggers an early increased expression of factors contributing to the innate immune defense in the udder of the cow. Vet. Res. $39: 18$.

Pfaffl, M. W. 2001. Development and validation of an externally standardised quantitative insulin like growth factor-1 (IGF-1) RTPCR using LightCycler SYBR ${ }^{\circledR}$ Green I technology. Pages $281-$ 292 in Rapid Cycle Real-Time PCR, Methods and Applications. S.
Meurer, C. Wittwer, and K. Nakagawara, ed. Springer, Heidelberg, Germany.

R Development Core Team. 2008. R: A Language and Environment for Statistical Computing. R Foundation for Statistical Computing, Vienna, Austria.

Regenhard, P., M. Leippe, S. Schubert, R. Podschun, E. Kalm, J. Grötzinger, and C. Looft. 2009. Antimicrobial activity of bovine psoriasin. Vet. Microbiol. 136:335-340.

Roosen, S., K. Exner, S. Paul, J. M. Schröder, E. Kalm, and C. Looft. 2004. Bovine beta-defensins: Identification and characterization of novel bovine beta-defensin genes and their expression in mammary gland tissue. Mamm. Genome 15:834-842.

Rupp, R., and D. Boichard. 2003. Genetics of resistance to mastitis in dairy cattle. Vet. Res. 34:671-688.

Russell, J. P., G. Diamond, A. P. Tarver, T. F. Scanlin, and C. L. Bevins. 1996. Coordinate induction of two antibiotic genes in tracheal epithelial cells exposed to the inflammatory mediators lipopolysaccharide and tumor necrosis factor alpha. Infect. Immun. 64:1565-1568.

Ryan, L. K., J. Rhodes, M. Bhat, and G. Diamond. 1998. Expression of beta-defensin genes in bovine alveolar macrophages. Infect. Immun. 66:878-881.

Ryniewicz, Z., L. Zwierzchowski, E. Bagnicka, K. Flisikowski, A. Maj, J. Krzyzewski, and N. Strzalkowska. 2003. Association of the polymorphism at defensin gene loci with dairy production traits and milk somatic cell count in Black-and-White cows. Anim. Sci. Pap. Rep. 21:209-222.

Ryniewicz, Z., L. Zwierzchowski, E. Bagnicka, J. Krzyzewski, and N. Strzalkowska. 2002. Preliminary investigations on the polymorphism of defensin genes in cattle - Relation with milk somatic cell count. Anim. Sci. Pap. Rep. 20:125-131.

Schönwetter, B. S., E. D. Stolzenberg, and M. A. Zasloff. 1995. Epithelial antibiotics induced at sites of inflammation. Science $267: 1645-1648$

Selsted, M. E. 2004. Theta-defensins: Cyclic antimicrobial peptides produced by binary ligation of truncated alpha-defensins. Curr. Protein Pept. Sci. 5:365-371.

Swanson, K., S. Gorodetsky, L. Good, S. Davis, D. Musgrave, K. Stelwagen, V. Farr, and A. Molenaar. 2004. Expression of a beta-defensin mRNA, lingual antimicrobial peptide, in bovine mammary epithelial tissue is induced by mastitis. Infect. Immun. 72:7311-7314.

Tang, Y. Q., J. Yuan, G. Osapay, K. Osapay, D. Tran, C. J. Miller, A. J. Ouellette, and M. E. Selsted. 1999. A cyclic antimicrobial peptide produced in primate leukocytes by the ligation of two truncated alpha-defensins. Science 286:498-502.

Tarver, A. P., D. P. Clark, G. Diamond, J. P. Russell, H. ErdjumentBromage, P. Tempst, K. S. Cohen, D. E. Jones, R. W. Sweeney, M. Wines, S. Hwang, and C. L. Bevins. 1998. Enteric beta-defensin: Molecular cloning and characterization of a gene with inducible intestinal epithelial cell expression associated with Cryptosporidium parvum infection. Infect. Immun. 66:1045-1056.

Weller, J. I., A. Saran, and Y. Zeliger. 1992. Genetic and environmental relationships among somatic cell count, bacterial infection, and clinical mastitis. J. Dairy Sci. 75:2532-2540.

Wojdak-Maksymiec, K., M. Kmiec, and A. Zukiewicz. 2006. Associations between defensin polymorphism and somatic cell count in milk and milk utility traits in Jersey dairy cows. J. Vet. Med. A Physiol. Pathol. Clin. Med. 53:495-500.

Xiao, Y., A. L. Hughes, J. Ando, Y. Matsuda, J. F. Cheng, D. SkinnerNoble, and G. Zhang. 2004. A genome-wide screen identifies a single beta-defensin gene cluster in the chicken: Implications for the origin and evolution of mammalian defensins. BMC Genomics 5:56.

Yang, D., A. Biragyn, D. M. Hoover, J. Lubkowski, and J. J. Oppenheim. 2004. Multiple roles of antimicrobial defensins, cathelicidins, and eosinophil-derived neurotoxin in host defense. Annu. Rev. Immunol. 22:181-215. 